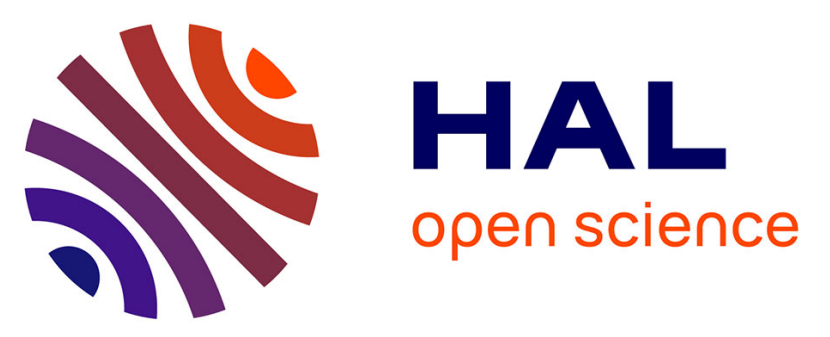

\title{
A response to H.F.V. Cardoso's 2019 "A critical response to "A critical review of sub-adult age estimation in biological anthropology" by Corron, Marchal, Condemi and Adalian (2018)"
}

L. Corron, F. Marchal, Silvana Condemi, Pascal Adalian

\section{To cite this version:}

L. Corron, F. Marchal, Silvana Condemi, Pascal Adalian. A response to H.F.V. Cardoso's 2019 "A critical response to "A critical review of sub-adult age estimation in biological anthropology" by Corron, Marchal, Condemi and Adalian (2018)". Forensic Science International, 2020, 313, pp.110368. 10.1016/j.forsciint.2020.110368 . hal-03053150

\section{HAL Id: hal-03053150 \\ https://hal-amu.archives-ouvertes.fr/hal-03053150}

Submitted on 5 Jan 2021

HAL is a multi-disciplinary open access archive for the deposit and dissemination of scientific research documents, whether they are published or not. The documents may come from teaching and research institutions in France or abroad, or from public or private research centers.
L'archive ouverte pluridisciplinaire HAL, est destinée au dépôt et à la diffusion de documents scientifiques de niveau recherche, publiés ou non, émanant des établissements d'enseignement et de recherche français ou étrangers, des laboratoires publics ou privés.

\section{(1) (1) $\$$}

Distributed under a Creative Commons Attribution - NonCommercial - NoDerivatives $\mid 4.0$ 


\section{A response to H.F.V. Cardoso's 2019 “A critical response to "A critical review of sub-adult age estimation in biological anthropology" by Corron, Marchal, Condemi and Adalian (2018)"}

L. Corron* Department of Anthropology, University of Nevada, Reno, USA

F. Marchal S. Condemi P. Adalian ADES - Anthropologie bioculturelle, Droit, Ethique et Santé, UMR 7268, EFS, CNRS, Faculté de Médecine, Université Aix-Marseille, 13 344, Marseille cedex 15, France

* Corresponding author at: Department of Anthropology, University of Nevada, Reno, 1664 N Virginia St MS 0096, Reno, NV 89557, USA. E-mail address: Icorron@unr.edu (L. Corron).

\section{Letter to the Editor}

Although, as scientists, we strive to be as objective and exhaustive as possible in our work, we gladly accept that our papers can be openly and constructively criticized. Dr H.F.V. Cardoso's relatively contentious response [1] to our article "A critical review of sub-adult age estimation in biological anthropology, Forensic Sci Int 2018 288:328.e.1-328.e.9" shows that at least one person thought we were suggesting that only 7 of the 269 subadult age estimation publications we included in our analyses were "fit for use" in biological anthropology. Our paper was a critical review, and evidently not "The 7 and only methods that comply with published methodological recommendations for sub-adult age estimation in biological anthropology". Dr Cardoso's letter mainly reinforces the point we, the authors, made in our article: "The purpose [ ... ] was to draw attention to these difficulties pertaining to subadult age estimation and to illustrate that such publications are most often unfit, or at the very least questionable, for sub-adult age estimation in a forensic context [2, p.328.e.7]." However, his response indicates that we should have made this general take-home point more strongly and that some clarification is necessary.

Dr Cardoso pointed out several issues with our study that seem to be more focused on details of the study rather than its general scope.

One critique was about the composition of the corpus and the context of the publications included in it. These publications were chosen because they were available in libraries or online and were all published after some form of peer-review, be it by an editorial board or a bioanthropological scientific committee for conference papers. Therefore, not all publications were strictly found in peerreviewed journals but also in peer-reviewed conference proceedings and in published biological and forensic anthropology books, available either online or in various university library databases. The publications included age estimation of the living or the deceased in both forensic and bioarcheological contexts. Dr Cardoso states that some publications did not concern sub-adult age estimation, but rather adult age estimation, and/or could not be considered as sub-adult age estimation methods sensu stricto. Indeed, they all relate to post-natal sub-adult age estimation sensu largo. Although some methods do include adults in their training sample, all samples cover at least a few years between birth to late teensearly 20-something individuals, which is when the last ossification centers of the clavicle, iliac crest and ribs are still fusing. These "older' individuals are therefore still considered as immature or sub-adults from a biological perspective. In fact, these individuals and age indicators are the main focus of many forensic anthropology papers published on determining whether an individual is minor or not. 
In effect, not all of the publications in our corpus are sub-adult age estimation methods per se. For instance, some of them are atlases or reference data on skeletal and dental growth and development but they have been and are still being used as methods for sub-adult age estimation or indirectly applied as such in biological anthropology in both forensic and/or bioarcheological contexts. The reason for this is most likely multifactorial: it has historically been done and persists by habit, it depends on the elements available for analysis, which are covered more extensively by atlases and the like, and also on the accessibility of some newer methods and how easy they are to implement.

In our paper, we focused on method application in the forensic context, which is particularly sensitive to this methodological point, as we addressed it: "Methods must also comply to conditions of court admissibility [ . . . ] Methodological, ethical and legal discrepancies are therefore all potential sources of misestimation of age leading to possible errors of interpretation in forensic cases." [2, $p$ 328.e7]. Proposing a well-argued reasoning for publication selection in accordance with the fact that methods comply with published recommendations is an important argument in court. Whether these publications should be used for such purposes is a corollary question $\operatorname{Dr}$ Cardoso ponders, the answer to which we also explicitly address in our paper: "The goal of this study was not to provide a clear definition of what constitutes a sub-adult age estimation method, but rather to give an overview of what material is available to anthropologists today for sub-adult age estimation in biological anthropology and how they compare to one another based on a standardized scale [ . . . ] [2, p. 328.e7]." Indeed, one of the conclusions of our study is that not all of them should be used as sub-adult age estimation methods, which reinforces our point: users should be critical of all aspects of a publication, including its initial purpose and potential misapplications. That is also why we used the general term of "publication" instead of "method" in our paper. Finally, known or less-known publications based on any modality (e.g. dry bone, medical imaging, histology, biochemistry) were included to the corpus to cover the variety of approaches to sub-adult age estimation as exhaustively as possible. Although their application may be limited, and context- or case-specific, we did not consider this as an exclusion criterion.

The second main critique was that the set of ten parameters used to qualify the publications and the database itself, consisting in 269 publications on sub-adults and sub-adult age estimation, were non-exhaustive, as only ten common parameters were used to evaluate the publications, and that some of these parameters, such as minimum sample size, were "fabricated". We have not "fabricated" any of these parameters. As stated in our article [2], all ten parameters describing sampling (age, sex, age distribution, sex distribution, sample size) and statistical aspects of the publications (reliability, accuracy, precision, observer errors, validation) were adapted and summarized from published peer-reviewed recommendations, such as the work by Cunha et al. 2009 or Schmeling et al. 2007. These authors and the others explicitly present these parameters as guidelines for building standardized methods in forensic anthropology [3-6]. These articles highlight the importance of representativity but make no mention of a clear-cut minimum sample size required for validity. A few publications present several formulae to calculate minimum sample size for methods aimed at estimating the elements of the individual biological profile (age, sex, ancestry, stature) [e.g., 7, p. 314-315] but all depend on the number of individual categories (e.g. age and/or ancestry groups) and the number of indicators used as predictors. This means that a single value for sample size cannot be generalized for all age estimation methods, as it depends on the age range covered by the sample, the number and type of predictor variables, the type of analysis used and its sensitivity to sample size, and other factors. It is therefore 
almost entirely method-specific. Moreover, as Dr Cardoso pointed out with the example of Moorrees et al.'s, 1963 publication [8], sample size can vary within a given method ${ }^{1}$.

Large referenced sub-adult collections and sets of data were difficult to come by until the relatively recent dissemination and standardization of medical images in anthropological research. These new modalities result in the variety of sample sizes covered by the publications in our corpus, some of which go as far back as the 1920'-1930's. For these reasons, a somewhat subjective, but in no way "fabricated", decision /cut-off point of the "sample size" parameter's descriptor, not of the parameter itself, was made to enable analysis and method comparisons. By setting a valid sample size at 200 individuals or above, a lower number of publications would be "invalid" for that specific parameter, as we felt it was not as clear-cut as the other four. It is true that the number 200 was chosen as a compromise more than a definite standard. This is also clearly stated and discussed at length in our article. However, after rerunning the analyses with any sample size considered as valid (which in itself is extremely debatable), the results remained identical: the same seven out of the 269 publications respected all other valid parameters, meaning the cut-off point at 200 for sample size is not as influential on overall sampling and statistical validity as the other 9 parameters. However, to take into consideration sample representativity and still be able to compare publications based on that parameter, it was decided to keep that threshold for sample size.

Also part of Dr Cardoso's critique was that general rather than specific analyses pertaining to each publication were done, i.e. that different modes of method validation were clumped into one statistical parameter. We acknowledged this limitation in our paper but chose to do so for the purpose of clarity and to enable method comparison by using a limited number of homologous criteria. Overall, concerning these comments on the ten parameters used for method evaluation, our paper strongly and frequently emphasized that they should be considered by users to check each selected publication for all parameters before its application. In addition, although a method may be suitable in theory (i.e. all ten parameters are valid), it is not always the case in practice, as it depends on the context and the type of material available (e.g. it is based on histological slices, or it only applies to age estimation of the living). Finally, we showed that although the call for methodological rigor and standardization of sampling and statistical parameters was published within the forensic context [3-6], it seems reasonable to assume these principles would be applicable to any and all contexts in biological anthropology, as it is safe to say all anthropologists aim for the most accurate and reliable estimates of the biological profile.

Dr Cardoso also implied that our analyses were positively biased towards our own and our coworkers' publications, writing that our study was done to "insure that certain methods were left out or others were included in the list [1]." This brings us to his comment questioning the scientific integrity of our study: "Ultimately, it is surprising to see that 3 methods in the list of 7 are authored by Corron and co-workers and by some of Corron's co-authors. (Cardoso, 2019)". Our goal is to discuss, and possibly promote good methodological practices for building, selecting and applying sub-adult age estimation methods. Therefore, the methods we or our coworkers have published since the guidelines on sampling and statistical validity were first issued naturally strive to follow and respect them! As such, our efforts are put towards using samples composed of individuals of known age and sex; our publications explicitly present tests, tables and/or plots assessing even age and sex distributions; and the five statistical

\footnotetext{
${ }^{1}$ Although sample size for the central incisors is $n=134$ and $n=236$ for the rest of the dentition, the MFH method is still considered to respect the validity criteria of $n 200$, as this method is not recommended for use on a single tooth alone.
} 
parameters cited above comply with validity standards as presented in these published recommendations [9-11]. Whether these publications are suitable for use as sub-adult age estimation in any context is a different question that only the user can answer, as we clearly mentioned and advised in the paper.

Finally, Dr Cardoso suggested that we "provide the experts with the means to select the methods themselves, by critically reviewing the recommendations." We agree with this statement, which is why we published a follow-up article to do just that [12]: Sub-adult Aging Method Selection, or SAMS, is a freely accessible online decisional tool to assist biological anthropologists, and forensic anthropologists in particular, in critically selecting and evaluating sub-adult age estimation publications. Users have complete freedom in the process of method evaluation and more flexibility to select methods adapted to their case or context, as additional descriptive parameters, too variable to be of any analytical use in the first study [2] were included. As Dr Cardoso pointed out, and because of the limited access to certain relevant publications, our database is still incomplete. However, we trust that the biological anthropology community will help us fill that gap with any existing missing publications. They will be bi-annually implemented into the SAMS database along with any new publications on the topic. Although users will be absolutely free to select any method of their choice, because we aim to remain as objectively critical as possible in method selection and evaluation, they will still be informed on how much a publication on sub-adult age estimation respects the 10 parameters for methodological validity via the two parameters we set up to characterize the publications in SAMS: Validity, Relevance and Score (see http://osteomics.com/SAMS/ for more details).

\section{Funding}

This work was funded by Ministère Français de la Recherche et de l'Enseignement Supérieur.

\section{CRediT authorship contribution statement}

L. Corron: Conceptualization, Writing - original draft, Writing - review \& editing.

F. Marchal: Conceptualization, Writing - review \& editing.

S. Condemi: Conceptualization, Writing - review \& editing.

P. Adalian: Conceptualization, Writing - review \& editing.

\section{References}

[1] H.V. Cardoso, A critical response to "A critical review of sub-adult age estimation in biological anthropology" by Corron, Marchal, Condemi and Adalian (2018). Letter to the Editor, Forensic Sci. Int. (July) (2019)109881, doi: http://dx.doi.org/10.1016/i.forsciint.2019.109881.

[2] L. Corron, F. Marchal, S. Condemi, P. Adalian, A critical review of sub-adult age estimation in biological anthropology: Do methods comply with published recommendations? Forensic Sci. Int. 288 (2018) 328.e.1-328.e.9. 
[3] D. Franklin, Forensic age estimation in human skeletal remains: current concepts and future directions, Legal Med. 12 (1) (2010) 1-7.

[4] E. Cunha, E. Baccino, L. Martrille, F. Ramsthaler, J. Prieto, Y. Schuliar, N. Lynnerup, C. Cattaneo, The problem of aging human remains and living individuals: a review, Forensic Sci. Int. 193 (2009) 1-13.

[5] F.W. Rösing, M. Graw, B. Marré, S. Ritz-Timme, M.A. Rothschild, K. Rötzscher, A. Schmeling, I. Schröder, G. Geserick, Recommendations for the forensic diagnosis of sex and age from skeletons, Homo 58 (1) (2007) 75-89.

[6] A. Schmeling, G. Geserick, W. Reisinger, A. Olze, Age estimation, Forensic Sci. Int. 165 (2-3) (2007) 178-181.

[7] S.D. Ousley, R.L. Jantz, Fordisc 3 and statistical methods for estimating sex and ancestry, in: D. Dirkmaat (Ed.), A Companion to Forensic Anthropology, Wiley, 2012, pp. 311-329 Chapter 15.

[8] C.F.A. Moorrees, E.A. Fanning, E.E. Hunt, Age variation of formation stages for ten permanent teeth, J. Dent. Res. 42 (1963) 1490-1502.

[9] L. Lalys, P. Adalian, K. Chaumoitre, M. Signoli, G. Leonetti (Eds.), Biométrie radiologique des os de la main : application à l'estimation de l'âge des individus immatures. 8emes Journées d'anthropologie de Valbonne, APDCA CNRS CEPAM, Valbonne, France, 2006.

[10] M. Daumas, K. Chaumoitre, P. Adalian, F. Marchal, Bidimensional data allow for better age estimation on immature specimens than unidimensional data: a preliminary study on the ilium, J. Forensic Sci. 61 (2) (2016) 394-401.

[11] L. Corron, F. Marchal, S. Condemi, K. Chaumoitre, P. Adalian, A new approach of juvenile age estimation using measurements of the ilium and Multivariate Adaptive Regression Splines (MARS) models for better age prediction, J. Forensic Sci. 62 (1) (2017) 18-29.

[12] L. Corron, P. Adalian, S. Condemi, F. Marchal, D. Navega, Sub-adult aging method selection (SAMS): a decisional tool for selecting and evaluating subadult age estimation methods based on standardized methodological parameters, Forensic Sci Int. Jul 26 (2019)109897, doi:http://dx.doi.org/ 10.1016/j.forsciint.2019.109897.

Received 12 May 2020 Received in revised form 27 May 2020 Accepted 12 June 2020 Available online 15 June 2020 Editorial / Forensic Science International 313 (2020) 1103683 